\title{
Modeling Absolute and Allometric Growth in Houbara Bustard (Chlamydotis undulata undulata) in Captivity
}

\author{
Amal Korrida ${ }^{1,2,}$, Samuel N. Nahashon ${ }^{3}$, Amal Amin-Alami ${ }^{2}$, Sami Jadallah', and Samuel E. \\ Aggrey $^{4}$
}

${ }^{1}$ HRH Prince Sultan Bin Abdul Aziz Al Saud International Foundation for Conservation and Development of Wildlife, Genetics department, Agadir 80350, Morocco; ${ }^{2}$ Laboratoire des Substances Naturelles, Faculté des Sciences d'Agadir, Équipe d'Océanographie Biologique, Université lbn Zohr, Agadir, Maroc ; ${ }^{3}$ Department of Agriculture, University of Tennessee, Nashville, TN, USA; ${ }^{4}$ Department of Poultry Science, University of Georgia, Athens, GA 30602-2772, USA.

Received: April 11, 2012 / Accepted: May 6, 2012

\begin{abstract}
Absolute and allometric growth of Houbara Bustard (Chlamydotis undulata undulata) were studied. Using body weight measurements from hatch till 120 days of age, the Gompertz-Laird growth model was used to describe the growth pattern of the Houbara. Whereas the model underpredicted the hatching weight ( 34 vs $40 \mathrm{~g}$ ), the predicted asymptotic body weight was in concordance with the data (1193 g). The same growth model was also used to describe the growth pattern of beak and shank length, chest girth and wing span. The beak reached asymptotic length faster than the shank, chest girth and wing span. We used the log transformed relationship of Huxley to determine the allometric relationship of beak length, shank length, chest girth and wing span relative to body weight from hatch to 120 days. The allometric growth analysis indicated that, beak length, shank length, chest girth and wing span all followed a hypometric allometry $(b<1)$ relative to body weight growth. However, the wing span has the highest allometric growth compared to the other measurements indicating the evolutionary importance of developing wings for quick flights from predators.

Keywords: Houbara Bustard, Gompertz model, allometry, growth, captive breeding.
\end{abstract}

*Corresponding author: amalkorrida11@aol.com

\section{Introduction}

The Houbara Bustard (Chlamydotis undulata) is a medium sized Bustard of the Otididae family which breeds in deserts and arid sandy areas with relatively large range of habitats. The Houbara Bustard species can be found in the Canary Islands (Chlamydotis undulata fuertaventurae) and North Africa (Chlamydotis undulata undulata) from Morocco to Egypt, whereas the Macqueen's species (Chlamydotis macqueenii) occurs in the Middle East, and Asia (Iran, India, Pakistan, Kazakhstan and China). The two species are the prized quarry for Arab falconers, and widespread hunting and loss of habitat have greatly reduced their numbers. The International Union for Conservation of $\mathrm{Na}$ ture (IUCN, 2011) classifies the Houbara species as vulnerable. The Houbara is also prohibited from international trade (CITES, 2012).

Since the early 1990s, several conversation centers have been established in Northern Africa and the Middle East to propagate the Houbara and Macqueen's in captivity and establish proper conservation practices in order to preserve the Houbara. Since then there have been studies on the biology (Saint Jalme et al., 1994; Tieleman et al., 2002), captive breeding (Gélinaud et al., 1997; Hémon et al., 2000) diseases (Ostrowski et al., 1995; Bailey et al., 2008), ecology (van Heezik and Ostrowski, 2001), behavior (Gaucher et al., 1996, van Heezik and Seddon, 1998), genetics (Chbel et al., 2002; Idaghdour et al., 2004; Lesobre et al., 2010) and phylogeny (Granjon 
et al., 1994; Broders et al., 2003) of the Houbara. However, data on the entire growth characteristics of the Houbara is very scant. This is because most of the Houbara bred in captivity are released into the wild at the middle or end of the breeding season. To date, only few studies exist on the juvenile growth characteristics of the Houbara and Macqueen's (Lawrence et al., 1999; van Heezik and Seddon, 2001; Stiévenart, 2002).

Prediction of growth patterns has been studied extensively in other avian species, especially domestic fowl (Grossman and Bohren, 1982; Barbato, 1991; Aggrey, 2002; Aggrey, 2004). Growth comprises of hyperplasia, hypertrophy, cell division and apoptosis, however, these processes can also be affected by environmental fluctuations, dietary status, diseases and other by random events causing growth to fluctuate thereby making the study at a single point unattractive. Also, the pattern of growth reflects the architecture of body composition (Aggrey, 2002). In a species, such as the Houbara, the body weight at sexual maturity may become important because of the difference in growth patterns. Mathematical equations have been used to model growth characteristics (e.g., Gompertz, 1925; Richards, 1959). Growth characteristics derived from such mathematical equations smoothens body weigh fluctuations and uses previous and future weights to predict age-weight points (DeNise and Brinks, 1985).

The objective of this study was to use the Gompertz model to determine multiple growth phases, and asymptotic growth of the Houbara, and also determine the allometric growth of the beak length, shank length, chest girth, and wing span relative to body weight.

\section{Materials and Methods}

\section{Flock and Experimental Design}

Data were collected on a total of 178 birds that were hatched from a captive breeding program at HRH Prince Sultan Bin Abdul Aziz Al Saud International Foundation for Conservation and Development of Wildlife (IFCDW). The Houbara Bustards hatched and were raised from eggs laid by a captive-bred flock vaccinated against the avian poxvirus using an attenuated live vaccine and against the Newcastle disease virus (NDV) using an inactivated vaccine. The Houbara chicks were raised artificially and handfed every 2 hours for 14 days with a diet consisting of wet poultry meat extruded pellets ( $25 \%$ crude protein; $1.5 \%$ calcium, $1 \%$ phosphorus, $20,000 \mathrm{IU}$ vitamin A, $2,000 \mathrm{IU}$ vitamin D3, and 200 IU vitamin E), supplemented with meal worms (Tenebrio molitor), crickets (Grillus bimaculatus), carrots, minced meat and fresh alfafa. Feed crumbs were always available to stimulate pecking at food. The chicks were raised indoors in small boxes in groups of 3 or 4 at $25^{\circ} \mathrm{C}$. After 7 days, they are moved into an outdoor facility with very small pebble gravels as substrate and hereafter, transitioned into feeding independently and stimulate locomotion. The chicks were monitored at feeding times and abnormalities were reported to veterinarians who attended to them immediately. Body weight, beak length, shank length, chest girth (circumference at the largest portion of the breast) and wing span were measured on day of hatch, days
$14,30,60,90$ and 120 . Wing span was measured by placing the bird on its feet and the wings held at the wrist joints, and the distance was measured between the tips of the longest primary feathers on each wing.

\section{Absolute Growth Model}

In order to estimate the expected body weight, beak length, shank length, chest girth and wing span at a specific age, the Laird form of the Gompertz equation (Laird et al., 1965) was fitted to the data. The following Gompertz equation was used to describe the data:

$$
W_{t}=W_{0} e^{\frac{L}{K}\left(1-e^{-K t}\right)}
$$

Where, $W_{t}$ is the measurement, e.g. body weight of bird at age $t, W_{0}$ is the initial (hatch) measurement, $L$ is the instantaneous growth rate (per day), $K$ is the rate of exponential decay of the initial specific growth rate, $L$, which measures the rate of decline in the growth rate. The asymptotic measurement $W_{A}$ was derived as:

$$
W_{A}=W_{0} e^{\frac{L}{K}}
$$

Growth curve parameters were estimated using PROC NLIN (Marquart algorithm) (SAS Inst. Inc., (2002).

\section{Scaling Relationships}

We tested the hypotheses on the scaling of beak length, shank length, wing span, and chest girth on body weight using the power function $Y=a x^{b}$ (Huxley, 1932) in its log transformed form:

$$
\operatorname{Ln}(Y)=\operatorname{Ln}(a)+b \operatorname{Ln}(x)
$$

In isometric relationships, the expected slope (b) is 1.0 as both $Y$ and $x$ are of linear dimension. We analyzed all linear relations using reduced major axis (RMA) regression because it accounts for the error in the 'independent' variable (Sokal and Rohlf, 1995). The RMA regression coefficients were computed using RMA for JAVA v. 1.21 (Bohonak and van der Linde, 2008).

\section{Results and Discussion}

The means and standard deviations for body weight, shank length, wing span and chest girth are presented in Table 1. Like most longitudinal data, the standard deviations increased with age. The means and standard errors (SE) of growth and body dimensions predicted with the Gompertz model are presented in Table 2. Except for beak length, the Gompertz model underpredicted the hatching measurements. The hatching weight predicted by the Gompertz model $(34.5 \mathrm{~g})$ was lower than the measured weight $(40.3 \mathrm{~g})$. The underprediction of initial measurement is a common feature of most growth models, and as a result, Grossman and Bohren (1982) suggested constraining the initial measurement. However, Pasternak and Shalev (1994) recommended weighting the initial measurement by the inverse 
Table 1. Means ( $\pm S D$ ) for body weight $(B W)$, beak length ( $B L)$, shank length $(S L)$, wing span $(W S)$, and chest girth (CG) at different ages in Houbara Bustard ( $N=178)$.

\begin{tabular}{lcrlrrl}
\hline Age (days) & \multicolumn{1}{l}{ BW $(\mathbf{g})$} & & BL $(\mathbf{c m})$ & \multicolumn{1}{l}{$(\mathbf{S L}) \mathbf{c m}$} & WS $(\mathbf{c m})$ & CG $(\mathbf{c m})$ \\
\hline 0 & $40.33 \pm$ & 4.85 & $1.46 \pm 0.21$ & $1.95 \pm 0.23$ & $10.82 \pm 0.72$ & $10.11 \pm 0.94$ \\
7 & $65.22 \pm 10.17$ & $2.03 \pm 0.21$ & $2.77 \pm 0.29$ & $16.93 \pm 2.06$ & $12.13 \pm 1.09$ \\
14 & $146.79 \pm 22.93$ & $2.60 \pm 0.25$ & $3.67 \pm 0.35$ & $30.02 \pm 3.84$ & $14.82 \pm 1.27$ \\
30 & $408.89 \pm 59.52$ & $3.36 \pm 0.30$ & $5.84 \pm 0.48$ & $69.90 \pm 9.69$ & $21.56 \pm 2.26$ \\
60 & $852.35 \pm 128.29$ & $3.94 \pm 0.38$ & $8.32 \pm 0.55$ & $106.07 \pm 6.70$ & $30.36 \pm 2.89$ \\
90 & $1026.21 \pm 176.71$ & $4.03 \pm 0.33$ & $8.97 \pm 0.60$ & $115.35 \pm 5.23$ & $31.66 \pm 2.71$ \\
120 & $1194.06 \pm 213.51$ & $4.17 \pm 0.41$ & $8.85 \pm 0.54$ & $116.09 \pm 6.24$ & $32.46 \pm 3.24$ \\
\hline
\end{tabular}

Table 2. Estimated coefficients (SE) and confident intervals (Cl) for Gompertz growth, beak length, shank length, wing span, and chest girth parameters in Houbara Bustard.

\begin{tabular}{|c|c|c|}
\hline Parameter & Coefficient & $95 \% \mathrm{Cl}$ \\
\hline \multicolumn{3}{|c|}{ Body Weight } \\
\hline Hatching weight $\left(W_{0}\right), g$ & $34.5326 \pm 2.96$ & $28.7329-40.3323$ \\
\hline Initial growth rate $\left(L_{B}\right), g / d$ & $0.1374 \pm 0.01$ & $0.1242-0.1506$ \\
\hline Rate of decay $\left(K_{B}\right), g / d$ & $0.0388 \pm 0.00$ & $0.0366-0.0410$ \\
\hline Asymptotic weight ${ }^{1}\left(W_{A}\right), g$ & 1192.9300 & \\
\hline \multicolumn{3}{|c|}{ Beak Length } \\
\hline Hatching length $\left(B_{0}\right), \mathrm{cm}$ & $1.4569 \pm 0.02$ & $1.4219-1.4920$ \\
\hline Initial growth rate $\left(L_{b}\right), c m / d$ & $0.0598 \pm 0.00$ & $0.0562-0.0634$ \\
\hline Rate of decay $\left(K_{b}\right), c m / d$ & $0.0588 \pm 0.00$ & $0.0561-0.0616$ \\
\hline Asymptotic length ${ }^{1}\left(B_{A}\right), c m$ & 4.0248 & \\
\hline \multicolumn{3}{|c|}{ Shank Length } \\
\hline Hatching length $\left(\mathrm{S}_{0}\right), \mathrm{cm}$ & $1.8621 \pm 0.02$ & $1.8167-1.9076$ \\
\hline Initial growth rate $\left(L_{s}\right), \mathrm{cm} / \mathrm{d}$ & $0.0666 \pm 0.00$ & $0.0641-0.0692$ \\
\hline Rate of decay $\left(K_{s}\right), \mathrm{cm} / \mathrm{d}$ & $0.0418 \pm 0.00$ & $0.0406-0.0430$ \\
\hline Asymptotic Length ${ }^{1}\left(S_{A}\right), c m$ & 9.1546 & \\
\hline \multicolumn{3}{|c|}{ Wing Span } \\
\hline Hatching weight $\left(\mathrm{WS}_{0}\right), \mathrm{cm}$ & $7.3616 \pm 0.24$ & $6.8925-7.8307$ \\
\hline Initial growth rate $\left(L_{w s}\right), \mathrm{cm} / \mathrm{d}$ & $0.1509 \pm 0.00$ & $0.1441-0.1577$ \\
\hline Rate of decay $\left(K_{w s}\right), \mathrm{cm} / \mathrm{d}$ & $0.0545 \pm 0.00$ & $0.0531-0.0558$ \\
\hline Asymptotic length ${ }^{1}\left(W S_{A}\right), c m$ & 117.5562 & \\
\hline \multicolumn{3}{|c|}{ Chest Girth } \\
\hline Hatching girth $\left(G_{0}\right), \mathrm{cm}$ & $9.5129 \pm 0.11$ & $9.2951-9.7307$ \\
\hline Initial growth rate $\left(\mathrm{L}_{\mathrm{g}}\right), \mathrm{cm} / \mathrm{d}$ & $0.0430 \pm 0.00$ & $0.0407-0.0453$ \\
\hline Rate of decay $\left(K_{g}\right), \mathrm{cm} / \mathrm{d}$ & $0.0341 \pm 0.00$ & $0.0326-0.05772$ \\
\hline Asymptotic diameter ${ }^{1}\left(G_{A}\right), g$ & 33.5572 & \\
\hline
\end{tabular}

Table 3. Parameter from reduced maximum axis (RMA) regression estimates ( $\pm S E$ ) and confidence intervals $(\mathrm{Cl})$ of allometric growth of some morphometric characters, as a function of body weight in Houbara Bustard.

\begin{tabular}{lllllll}
\hline & Intercept & $\mathbf{9 5 \%} \mathbf{C l}$ & Slope & $\mathbf{9 5 \%} \mathbf{C l}$ & $\mathbf{R}^{\mathbf{2}}$ & Allometry \\
\hline Beak length & $-0.66 \pm 0.02$ & $-0.69--0.62$ & $0.31 \pm 0.00$ & $0.30-0.31$ & 0.8763 & Negative \\
Shank length & $-0.94 \pm 0.02$ & $-0.98--0.92$ & $0.45 \pm 0.00$ & $0.45-0.46$ & 0.9644 & Negative \\
Wing span & $-0.26 \pm 0.02$ & $-0.31--0.22$ & $0.73 \pm 0.01$ & $0.72-0.74$ & 0.9719 & Negative \\
Chest girth & $0.99 \pm 0.01$ & $0.96-1.01$ & $0.35 \pm 0.00$ & $0.35-0.36$ & 0.9571 & Negative \\
\hline
\end{tabular}

of the variance. The fits of the absolute growth measurements are presented in Figures 1, 2 and 3. It is expected that the lower the initial growth rate, the earlier the asymptotic measurement is reached (Aggrey, 2002). From the estimates in Table 2, body weight and wing span had the highest instantaneous rates compared to beak and shank lengths, and chest girth. Beak length reached its asymptote earlier than shank length (Figure 2). In the wild, the Houbara Bustard mainly feeds on seeds, invertebrates and small vertebrates, and underdevelopes beak to limit its ability to feed. Thus, the beak growing to maturity earlier than other measurements signifies its importance in early feeding ability and survival. The shank grew at a rate of $0.07 \mathrm{~cm}$ per day until the age of maximum growth, and hereafter, grew at $0.04 \mathrm{~cm}$ per day until maturity. Improper development of the 


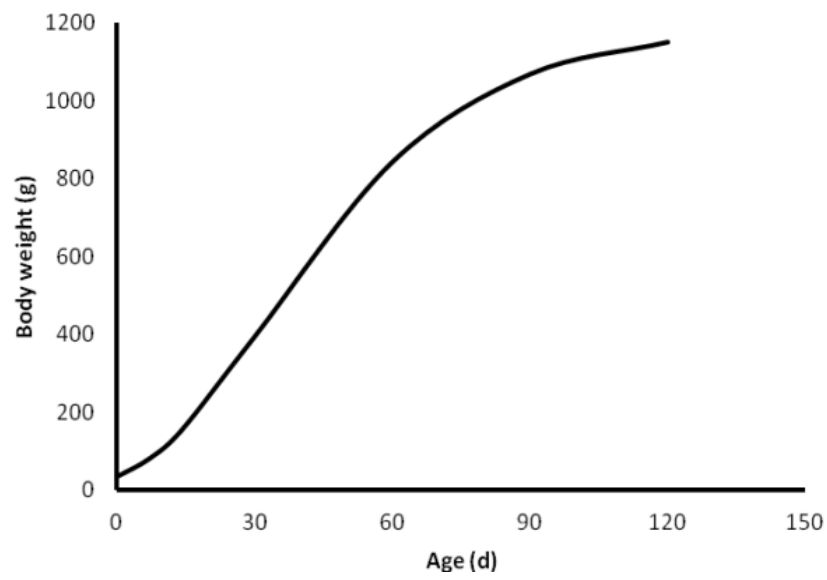

Figure 1. Growth curve of the Houbara Bustard predicted by the Gompertz model.

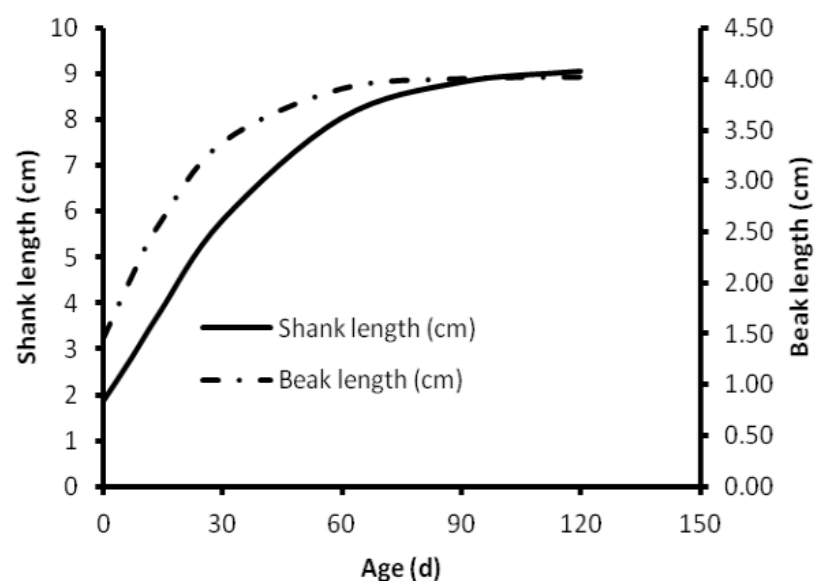

Figure 2. Beak and shank length curves of the Houbara Bustard predicted by the Gompertz model.

skeletal system can be significant in the health of the Houbara. According to Naldo et al., (1998), rotational and angular limb development, rolled toes and fractures are common limb abnormalities that affect Bustards. Growth analysis of the metatarsus, tibiotarsus and humerus in Houbara (Naldo et al., 2000) suggests the growth pattern of the shank in this study was within expectation of the general skeletal development of Houbaras.

The initial growth rate of the chest girth lags behind wing span and overall growth. Wing span has the highest initial growth rate compared to the overall growth. In the wild, the Houbara makes high thrust initial flight from predators but these flights are of shorter durations. Perhaps the initial growth rate allows them to develop wing span necessary for such high thrust flights, but underdeveloped keel could be responsible for their short duration. Similar to most avian species (Barbato, 1991; Aggrey, 2002), the correlation between the $L$ and $K$ growth parameters are high ( $r=0.92-0.96)$.

The literature is scant on growth characteristics and modeling in the Houbara Bustard, however, graphical representation of growth by Naldo et al., (2000) suggests that the growth data

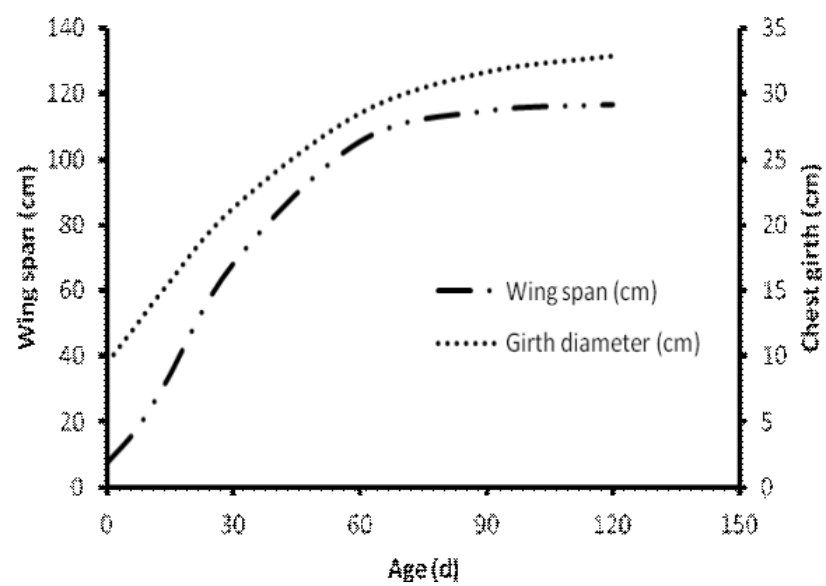

Figure 3. Wing span and girth circumference curves of the Houbara Bustard predicted by the Gompertz model.

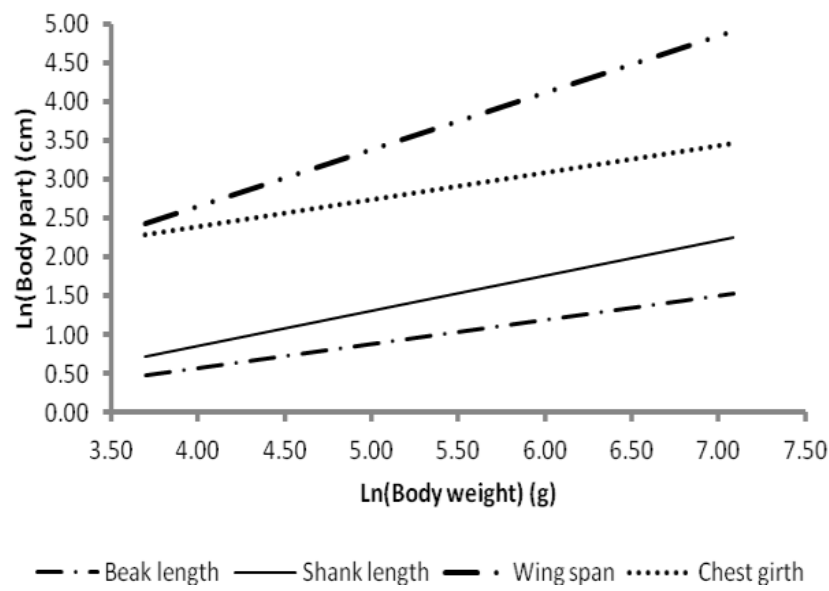

Figure 4. Allometric growth functions of beak length, shank length, wing span and chest girth versus body weight.

from the current study was in concordance with expectation. Even though the Houbara exhibit sexual dimorphism, the birds used in this study were not sexed. Future studies should include gender and data should be conducted for a longer duration to encompass both summer and winter in order to understand how the Houbara regulate its body weight through different seasons.

Allometry allows for the study of the proportional change in the dimensions of one character relative to another. In essence, it is the scaling relationship between characters. The log transformed relationship of Huxley (1932) often reveals linear allometry with a slope of b (Figure 4), and such allometries are classified according to the value of $b$. Characters scale hypometrically when $b<1$, isometrically, when $b=1$, and hypermetrically when $b>1$. The scaling exponent of the allometric analysis indicated that the beak, girth, shank, and wing span all exhibited negative allometric growth in relation to body weight (Table 3 , Figure 4). However, of all the parts measured, the wing grew fastest compared to the beak in relation to body weight. The disproportionate growth of different parts of the body relative to body weight is an indication of the relative importance of the 
different parts to the survival of the Houbara. In early development, the beak and shank are relatively important to foraging and locomotion as the parents shelter the chicks against predators. However, the wing span has the highest allometric growth compared to the other measurements indicating the evolutional importance of developing wings for quick flights from predators.

Captive breeding of Houbara Bustard is arduous, and survival of the hatchling is crucial. Hand-feeding of chicks may introduce variation in chick body weight especially when there are multiple gamekeepers undertaking the feeding. Nevertheless, this study presents the first unique insight into the absolute growth and allometric growth characteristics of the Houbara. The average hatching weight was about $40 \mathrm{~g}$, and by 4 months, the average body weight was approximately $1200 \mathrm{~g}$. The beak reaches mature length faster than shank, chest girth and wings, however, the wing span even though has a negative allometry to body weight, still grows faster than the beak, shank and chest girth illustrating the evolutionary importance of developing an appropriate sized wings for quick but short flights from potential predators.

\section{Acknowledgements}

The authors dedicate the present study to the late Crown Prince, His Royal Highness Prince Sultan Bin Abdul Aziz Al Saud, sponsor and patron of the Foundation for his dedications, leadership and generosity to the environment and protection of wildlife. We would like also to extend our gratitude to Sheikh Mohamed Bin Khalid Bin Hethlain for his supports and encouragements. This work was made possible also by the support of colleagues and technical staff from IFCDW in Agadir and DERS in Errachidia centers, especially $A, S$ and $S$. Bouaich, M and A. Agouram, $H$. Idaghdour, A. Bayla, J. Amghar, S. Boucham, A. Zagmouz, A. El Abbassi, L and H. Gaboula, Y. Redouane, D. Moujani, Y. Debiani, M. Lahrar and A. Louzani. We thank also the anonymous referees for reviewing and evaluating this manuscript. This work is a part of the doctoral thesis of Amal Korrida on Houbara Bustard genetics.

\section{References}

Aggrey SE (2002) Comparison of three nonlinear and spline regression models for describing chicken growth curves. Poultry Science 81: $1782-1788$.

Aggrey SE (2004) Modelling the effect of nutritional status on preasymptotic and relative growth rates in a random-bred chicken population. J Anim Breed Genet 121: 260-268.

Bailey TA, P McKinney, and C Stiévenart (2008) Neonatal Diseases. In Disease and medical management of Houbara Bustards and other Otididae. Bailey TA Ed. (Emirates Printing Press LLC, Dubai), 301 317.

Barbato GF (1991) Genetic architecture of growth curve parameters in chickens. Theor Appl Genet 83: 24-32.

Bohonak AJ, and K van der Linder (2008) RMA for JAVA v.1.21. http:// www.bio.sdsu.edu/pub/andy/RMA.html (Accessed October 10, 2011).

Broders O, T Osborne, and M Wink (2003) A mtDNA phylogeny of
Bustards (family Otididae) based on nucleotide sequences of the cytochrome b-gene. J Ornithol 144: 176-185.

Chbel F, D Broderick, Y Idaghdour, A Korrida, and P McCormick (2002) Characterization of 22 microsatellites loci from the endangered Houbara Bustard (Chlamydotis undulata undulata). Molecular Ecology Notes 2: 484-487.

CITES (2012) The convention on international trade in endangered species of wild fauna and flora. (www.cites.org).

DeNise RSK, and JS Brinks (1985) Genetic and environmental aspects of growth curve parameters in beef cows. J Anim Sci 61: 14311440.

Gaucher P, P Paillat, C Chappuis, M Saint Jalme, F Lotfikhah, and M Wink (1996) Taxonomy of the Houbara Bustard Chlamydotis undulata subspecies considered on the basis of sexual display and genetics divergence. Ibis 138: 273-282.

Gélinaud G, $\bigcirc$ Combreau, and PJ Seddon (1997) First breeding success in captive-born reintroduced Houbara Bustards. Journal of Arid Environments 35: 527-534.

Gompertz B (1925) On the nature of the function expressive of the law of human mortality, and on a new method of determining the value of life contingencies. Phil Trans Royal Soc 115: 513-585.

Granion L, P Gaucher, A Greth, P Paillat, and M Vassart (1994) Allozyme study of two subspecies of Houbara Bustards (Chlamydotis undulata undulata). Biochemical Systematics and Ecology 22: 775 779.

Grossman M, and BB Bohren (1982) Comparison of proposed growth curve functions in chickens. Growth 46: 259-274.

Hémon S, P Paillat, Y van Heezik, and J Judas (2000) Captive breeding of Houbara Bustard in Saudi Arabia: 11 successful years. Bristish Poultry Science. Special Issue: Proceedings of the International Conference on Bird Reproduction, Tours, France, September 1999, Volume 41, Supplement 1 S49-S50.

Huxley JS (1932) Systematics of lizard family Pygopodidae with implications for the diversification of Australian temperate biotas. Syst Biol 52: 757-780.

Idaghdour Y, D Broderick, A Korrida, and F Chbel (2004) Mitochondrial control region diversity of the Houbara Bustard Chlamydotis undulata complex and genetic structure along the Atlantic Seabord of North Africa. Mol Ecol 13: 43-54.

IUCN (2011) The International Union for Conservation of Nature. (www. iucnredlist.org/)

Laird AK, SA Tyler, and AD Barton (1965) Dynamics of normal growth. Growth 29: 233-248.

Lawrence M, J Deag, and B Dawson (1999) Growth rates of Houbara Bustard chicks. IFCDW Annual Report, R.J.G Dawson and C. Lindsay edition (1999).

Lesobre L, F Lacroix, A Caizergues, Y Hingrat, T Chalah, and M Saint Jalme (2010) Conservation genetics of Houbara Bustard (Chlamydotis undulata undulata) : population structure and its implications for the reinforcement of wild populations. Conserv Genet 4: 1489 1497.

Naldo JL, TA Bailey, and JH Samour (1998) Musculoskeletal disorders in Bustard pediatric medicine. Journal of Avian Medicine and Surgery 12: 82-90.

Naldo JL, TA Bailey, and JH Samour (2000) Radiographic analysis of the growth rate of long bones in Bustards. Res Vet Sci 69: 233-240.

Ostrowski S, M Ancrenaz, M Saint Jalme, and A Greth (1995) Concurrent avian pox and Newcastle disease infection in a Houbara Bustard (Chlamydotis undulata). Avian Pathology 24: 573-577.

Pasternak H, and BA Shalev (1994) The effect of a feature of regression disturbance on the efficiency of fitting growth curves. Growth. Dev. Aging 58: 33-39. 
Richards FJ (1959) A flexible growth function for empirical use. J Exp Botany 10: 290-300.

Saint Jalme M, P Gaucher, and P Paillat (1994) Artificial insemination in Houbara Bustards (Chlamydotis undulata): influence of the number of spermatozoa and insemination frequency on fertility and ability to hatch. Journal of Reproduction and Fertility 100: 93-103.

SAS Institute (2002) SAS/STAT User's Guide. Version 6. 5th Edition. SAS Institute Inc., Cary, NC.

Sokal RR, and FJ Rohlf (1995) Biometry: The principles and practice of statistics in biological research. New York: W. H. Freeman.

Stiévenart C (2002) Monitoring of growth in Houbara Bustard Chlamydotis [undulata] macqueenii chicks. Proceedings of the 27th World Veterinary Congress (September 2002, Tunis) 178-179.
Tieleman BI, JB Williams, F Lacroix, and P Paillat (2002) Physiological responses of Houbara Bustards to high ambient temperatures. The Journal of Experimental Biology 2054: 503-511.

van Heezik Y, and S Ostrowski (2001) Conservation breeding for reintroductions: assessing survival in a captive flock of Houbara Bustards. Animal Conservation 4: 195-201.

van Heezik Y, and PJ Seddon (1998) Ontogeny of behaviour of handreared and hen-reared captive Houbara Bustards. Zoo Biology 17: 245-255.

van Heezik Y, and PJ Seddon (2001) Influence of group size and neonatal handling on growth rates, survival, and tameness of juvenile Houbara Bustards. Zoo Biology 20: 423-433. 